University of Nebraska - Lincoln

DigitalCommons@University of Nebraska - Lincoln

1980

\title{
Identification of Mosquitoes of Anopheles gambiae Species Complex A and B by Analysis of Cuticular Components
}

D. A. Carlson

USDA

M. W. Service

Liverpool School of Tropical Medicine

Follow this and additional works at: https://digitalcommons.unl.edu/entomologyother

Part of the Entomology Commons

Carlson, D. A. and Service, M. W., "Identification of Mosquitoes of Anopheles gambiae Species Complex A and B by Analysis of Cuticular Components" (1980). Entomology Papers from Other Sources. 13.

https://digitalcommons.unl.edu/entomologyother/13

This Article is brought to you for free and open access by the Entomology Collections, Miscellaneous at DigitalCommons@University of Nebraska - Lincoln. It has been accepted for inclusion in Entomology Papers from Other Sources by an authorized administrator of DigitalCommons@University of Nebraska - Lincoln. 
dition, cytotaxonomic identifications are difficult on preserved material with the result that many individuals cannot be identified (9). For allozyme studies it is necessary to keep field-collected samples continuously frozen in Dry Ice from time of collection until laboratory analysis.

We therefore investigated alternative methods of identifying adults of either sex of An. gambiae and An. arabiensis. Extraction and analysis of chemically stable and easily obtained cuticular hydrocarbons was carried out by gas chromatography (GC) to discover whether there were specific ingredients or unique relationships that could serve as markers. We report here some minor but statistically significant differences in the cuticular components of laboratory-reared adults of these two sibling species.

Sample of 2- to 3-week-old unmated mosquitoes were obtained from laboratory colonies of An. gambiae and $A n$. arabiensis maintained at the Liverpool School of Tropical Medicine in England.

Crude lipids were extracted from cuticular samples of individuals or pooled samples of each sex and species by soaking each sample twice in a minimum of $n$ heptane. The extract was transferred to a clean glass vial, and the solvent was removed for shipment by evaporation with a stream of dry air. Crude extracts were redissolved in a minimum amount of hexane $(10 \mu l)$ for immediate GC analysis (Fig. 1) or added to a column prepared from a disposable Pasteur pipette ( 5 $\mathrm{mm}$ in diameter), dry-packed with 60 to 200 mesh silica gel $(2 \mathrm{~cm})$ over 20 percent silver nitrate-impregnated silica gel (1 $\mathrm{cm})$. Saturated paraffins were eluted with $n$-hexane, olefins with 1 percent ether in hexane, and polyolefins with 15 percent ether in hexane. The volume of each separated sample was adjusted to $10 \mu \mathrm{l}$ for GC analysis (10).

The major constituents of the crude lipid extract were $n$-paraffins of 21 to 33 carbons and branched paraffins of 29 to 44 carbons, consistent with a previous analysis of pooled samples of 500 mosquitoes (11). Patterns in the chromatograms of components with 21 to 44 carbons appeared to be similar in all samples. Also in this range were smaller peaks, but none that appeared to be unique to either species or either sex. Saturated or unsaturated hydrocarbons that might be species markers were not found in sufficient quantities to be useful.

Quantitative data on the distribution of larger peaks suggests that there are at least three relationships that can be used for identification markers of females of occur sympatrically in many areas. They are true sibling species in which inter- breeding gives sterile males, and they the banding of the polytene chromosomes of either the fourth-instar larval nurse cells of (4) or the adult cently, however, a method has been dehas been tried, another procedure used for separating certain species of the gambiae complex $(7,8)$.

The usefulness of these methods for work in the field requires further evaluation because each has severe technical limitations. For example, only females can be identified by chromosomal studies, and they must be half-gravid. In ad- 


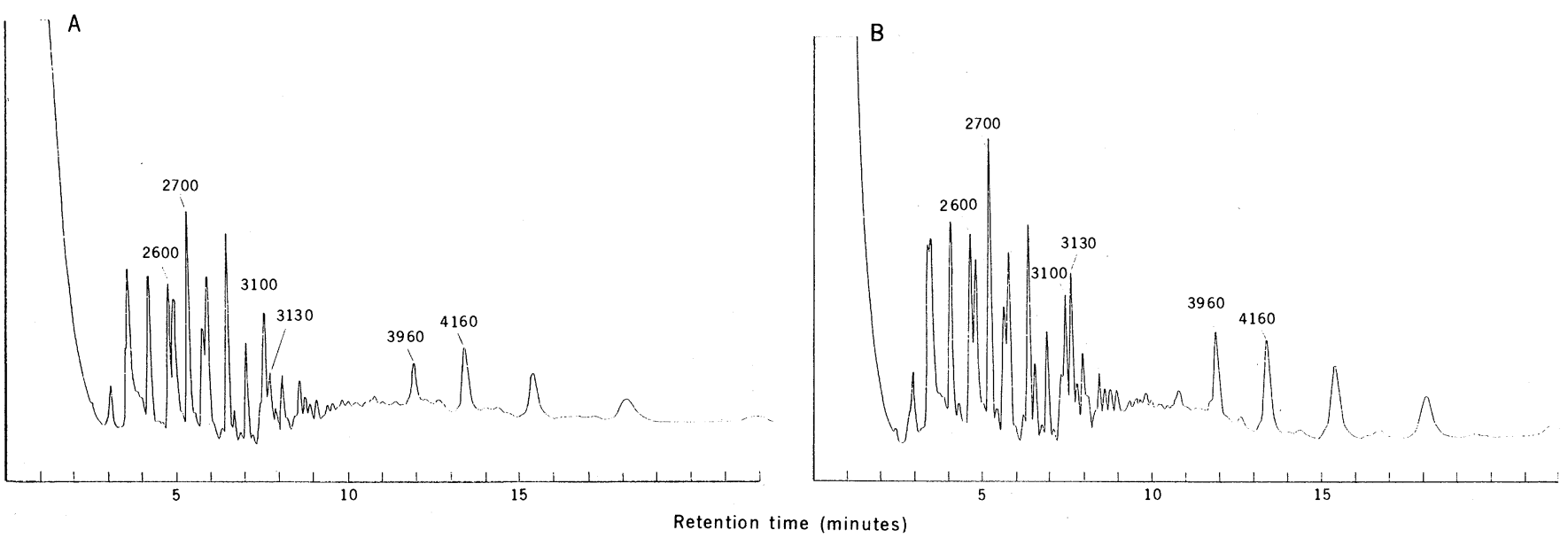

Fig. 1. Gas chromatograms of crude extracts from individual female Anopheles gambiae complex mosquitoes. (A) Anopheles gambiae. (B) Anopheles arabiensis.

these two species. One marker is the relative abundance $(R)$ of 26 and 27 carbon paraffins, that is, compared to $n$-heptacosane (KI 2700), the $R$ of $n$-hexacosane (KI 2600) was $0.69 \pm 0.07$ in crude extracts of single female An. gambiae but only $0.55 \pm 0.10$ in female An. arabiensis (Table 1). The ratios were significantly different by analysis of variance $(P<.05)(12)$.

A second marker is $R$ of peaks that elute with 13-methylhentriacontane (KI 3130 ) compared to $n$-hentriacontane (KI 3100 ). The values for $R$ for crude extracts of single females, $0.30 \pm 0.22$ for An. gambiae and $0.79 \pm 0.29$ for $A n$. arabiensis, were highly significantly different $(P<.005)$.

A third marker is the relative abundance of dimethylnonatriacontane (KI 3960) compared to dimethylhentetracontane (KI 4160) (13). The values for $R$ in crude extracts of single females,
$0.54 \pm 0.08$ for An. gambiae and 0.81 \pm 0.07 for $A n$. arabiensis, were highly significantly different $(P<.005)$. The elements in this set of values were well separated, and no overlapping values were seen.

Silica gel and argentation-liquid chromatography was conducted in attempts to improve resolution of peaks. Removal of nonparaffins by chromatography did not improve the analysis, as statistical significance declined between $R$ values for the first marker $(2600 / 2700)$ in paraffins from individual and pooled samples of females (Table 1). However, the differences in the second and third markers remained significant $(P<.05, P<.01)$ in paraffins from individual females and in paraffins from pooled females $(P<$ $.05, P<.005)$, respectively.

Crude cuticular extracts from single males were evaluated by the same procedures, and 2600/2700, 3130/3100, and

Table 1. Identification of An. gambiae and An. arabiensis by gas chromatography. Means and standard deviations are presented for relative abundances $(R)$ for females and males. Peaks were measured or quantitated electronically, and three pairs of peaks were selected and compared for each specimen or pooled sample.

\begin{tabular}{|c|c|c|c|c|c|}
\hline \multicolumn{2}{|c|}{$R 2600 / 2700$} & \multicolumn{2}{|c|}{$R 3130 / 3100$} & \multicolumn{2}{|c|}{$R 3960 / 4160$} \\
\hline $\begin{array}{c}\text { An. } \\
\text { gambiae }\end{array}$ & $\begin{array}{l}\text { An. } \\
\text { arabiensis }\end{array}$ & $\begin{array}{c}\text { An. } \\
\text { gambiae }\end{array}$ & $\begin{array}{c}\text { An. } \\
\text { arabiensis }\end{array}$ & $\begin{array}{c}\text { An. } \\
\text { gambiae }\end{array}$ & $\begin{array}{c}\text { An. } \\
\text { arabiensis }\end{array}$ \\
\hline \multicolumn{6}{|c|}{ Females: peaks in extracts of individuals $(\mathrm{N}=7)$} \\
\hline $0.69 \pm 0.07$ & $0.55 \pm 0.10^{*}$ & $0.30 \pm 0.22$ & $0.79 \pm 0.29 \dagger$ & $0.54 \pm 0.08 \ddagger$ & $0.81 \pm 0.07 \dagger$ \\
\hline \multicolumn{6}{|c|}{ Paraffins from individuals $(\mathrm{N}=5)$} \\
\hline \multicolumn{6}{|c|}{ Paraffins from pooled samples $(\mathrm{N}=5)$} \\
\hline $0.31 \pm 0.06$ & $0.18 \pm 0.21$ & $1.82 \pm 0.59 \S$ & $3.13 \pm 0.80 \ddagger *$ & $0.42 \pm 0.01$ & $0.73 \pm 0.06 \dagger$ \\
\hline \multicolumn{6}{|c|}{ Males: peaks in extracts of individuals $(\mathrm{N}=6)$} \\
\hline $0.74 \pm 0.09$ & $0.56 \pm 0.13^{*}$ & $0.30 \pm 0.09$ & $0.92 \pm 0.19 \dagger$ & $0.51 \pm 0.23 \ddagger$ & $0.74 \pm 0.14^{*}$ \\
\hline \multicolumn{6}{|c|}{ Paraffins from individuals $(\mathrm{N}=5)$} \\
\hline \multicolumn{6}{|c|}{ Paraffins from pooled sample $(\mathrm{N}=5)$} \\
\hline $0.49 \pm 0.10$ & $0.19 \pm 0.11 \dagger$ & $1.36 \pm 1.41 \S$ & $2.12 \pm 0.96 \S$ & $0.41 \pm 0.09$ & $0.80 \pm 0.08 \dagger$ \\
\hline
\end{tabular}

$3960 / 4160 R$ values were determined to be significantly different at $.05, .005$, and .05 levels, respectively (Table 1 ). With removal of nonparaffins, only the 3960/ 4160 values remained highly significantly different $(P<.005)$ in single males, while significant differences were retained in pooled paraffin samples $(P<$ .005 ) for both the $2600 / 2700$ and $3960 /$ 4160 values.

A correct identification could usually be made by observation of the chromatograms of crude extracts when unidentified nonparaffins contributed to peak height. Use of an automated data system is not obligatory because simple measurement of GC peak heights from the strip-chart recorder gave the same relative information used for 3130/3100 values in some samples.

It is more important to differentiate females than males because the females are vectors of disease, and females are more often caught than males. However, this simple technique was also successful when applied to males, even in the worst case when two of the three values were not significantly different. For example, when Fisher's method of combining tests (14) was applied to all three values of $R$ for paraffins from individual males, the significance was reduced slightly $(P<.05)$.

This technique is potentially useful for field-workers because cuticular hydrocarbons are chemically very stable, and it may be possible to utilize adults from light-trap collections, dead adults that are rather old, or even pinned specimens. To be most useful, the values obtained should be consistent over the range of the species. Although some variation between conspecifics may be expected, values found with individual mosquitoes may be consistent enough to observe with confidence values obtained for pooled samples $(11,15)$. 
These results merit detailed appraisal of the value of the cuticular components of wild adults for the separation of these and other sibling species of the An. gambiae complex, and perhaps other complexes, for example, species of the Culex pipiens or Aedes aegypti. Examination of materials from these and other mosquito species with the same techniques showed dissimilar distribution of components, suggesting that some cuticular components may possess biological activity related to species or sex recognition, or both. There is ample precedent for this in higher Diptera, because relatively nonvolatile cuticular hydrocarbons are responsible for male sexual stimulation and sex recognition in the tsetse fly (16) among others.

D. A. CARLSON

Insects Affecting Man and Animals

Research Laboratory, Agricultural

Research, Science and Education

Administration, U.S. Department of

Agriculture, Gainesville, Florida 32604

M. W. SERVICE

Department of Medical Entomology, Liverpool School of Tropical Medicine, Liverpool L3 5QA England

\section{References and Notes}

1. G. B. White, Mosq. Syst. 7, 303 (1975)

2. M. W. Service, ibid. 8, 217 (1976)

3. G. B. White Trans. R Soc. Trop. Med. Hyg. 68, 278 (1974).

4. M. Colluzi and A. Sabatini, Parassitologia 9,73 (1967).

5. M. Colluzi, ibid. 10, 179 (1968)

6. M Gatti, G. Santini, S. Pimpinelli, M. Colluzi, Heredity 38, 105 (1977).

7. R. J. Mahon, L. A. Green, R . H. Hunt, Bull. Entomol. Res. 66, 25 (1976).

8. S. J. Miles, $i$ bid. 68, 85 (1978).

9. M. W. Service, G. P. Joshi, G. D. Pradhan, Ann. Trop. Med. Parasitol. 72, 377 (1978).

10. The gas chromatograph (Varian model 1440) was equipped with a flame ionization detector, a Hewlett-Packard model 3380A integrator, and a $1.8 \mathrm{~m}$ by $2 \mathrm{~mm}$ (inner diameter) glass column $1.8 \mathrm{~m}$ by $2 \mathrm{~mm}$ (inner diameter) glass column 120 mesh Gas Chrom Q. Samples were analyzed with the column oven temperature prolyzed with the column oven temperature pro-
grammed to increase from $200^{\circ}$ to $335^{\circ} \mathrm{C}$ at grammed to increase from $200^{\circ}$ to $335^{\circ} \mathrm{C}$ at
$12^{\circ} \mathrm{C}$ per minute. Other parameters were: inject$12^{\circ} \mathrm{C}$ per minute. Other parameters were: injector port, $310^{\circ} \mathrm{C}$; detector, $385^{\circ} \mathrm{C}$. The carrier gas was helium, $20 \mathrm{ml} / \mathrm{min}$. Paraffin standards (Analabs) were used to ensure that the correct GC
peaks were being quantitated. Kovats indices KI values) were assigned to compounds eluting from a nonpolar $\mathrm{GC}$ column held at one temperature based on their retention times by using a log scale, relative to straight-chain (normal) saturated paraffins [E. Kovats, Adv. Chromatogr. $1,229(1965)]$. Thus a compound that coelutes with $n$-hentriacontane $\left(n \mathrm{C}_{3}\right)$ was assigned $\mathrm{KI}$ 3100. e center carbon a chain will typically add 30 units, that is, 13-methylhentriacontane had a KI of 3130 . The first fraction $(50 \mathrm{ml}$ of hexane eluted from a column of silver nitrate-silica gel) contained only saturated hydrocarbons for which KI values were dependent only on the number and location of branches on the chain and possibly the length of the branches.

11. D. A. Carlson and M. W. Service, Ann. Trop. Med. Parasitol. 73, 589 (1979).

12. R. G. Steel and J. H. Torrie, Principles and Procedures of Statistics (McGraw-Hill, New York, 1960).

13. Combined gas chromatography-mass spectrometry studies were conducted with a Varian 112 mass spectrometer interfaced to a Varian 3700 gas chromatograph fitted with a $3.6 \mathrm{~m}$ by $2 \mathrm{~mm}$ column of $\mathrm{OV}-101$ temperature programmed to increase at $3^{\circ} \mathrm{C}$ per minute from $160^{\circ}$ to $320^{\circ} \mathrm{C}$. Peaks at KI 2600, 2700, and 3100 were $n$-paraffins

SCIENCE, VOL. 207, 7 MARCH 1980 in An. arabienis females. The peak at KI 3130 in crude extracts was a mixture simplified by chromatography to leave two paraffins, 13- and 15-methylhentriacontane, with fragments at mass to charge $(\mathrm{m} / \mathrm{e})$ ratios of $196,224,252$ and 280 . The peak at KI 3960 contained 13,21 dimethylonatriacontane, which yielded fragments at $m / e$ 196, 280, and 407, and less of the 15,23 isomer, which yielded fragments a $m / e 224,252$, and 379 . The peak at KI 4160 contained 13,21-dimethylhentetracontane, which yielded fragments at m/e 196, 308, and 435, and less of the 15,23-isomer, which yielded fragments at $m / e$ 224, 280, and 407 .

14. R. A. Fisher, Statistical Methods for $R e$ search Workers (Oliver \& Boyd, ed, 11, London, 1950).

15. Several precautions were taken: polyethylene vial caps were scrupulously avoided, and GC column bleed was minimized by use of $\mathrm{OV}-1$ liquid phase in a carefully maintained glass column that was periodically treated with silylating agent to maintain about 3600 theroretical plates, $n$-pentatriacontane (KI 3500) being used for this calculation. An aluminum lining was used on the inner face of the GC septa to keep peaks from septum purge much smaller than the small peaks obtained from single mosquitoes.

16. D. A. Carlson, P. A. Langley, P. Huyton, Science 201, 750 (1978)

17. We thank N. Chen-Langenmayr for technical assistance, J. Seawright, M. Huettel, D. Joslyn, and L. Mukwaya for comments, C. Fatland for mass spectra, and D. Nelson for discussion.

6 September 1979; revised 5 November 1979 